\title{
Mamíferos da França Equinocial (Maranhão, Brasil)
}

\author{
Fernando Dias de Avila-Pires ${ }^{1}$
}

\begin{abstract}
During the XVI Century, France succeeded in establishing a few colonies in the Americas. Equinoctial France was a short-lived venture, but one that left an indelible mark upon the island of São Luis, in the State of Maranhão, Brazil. Two remarkable reports on the shape of the colony, its geographical features, climate, ethnography, botany, and zoology are among the first contributions to the natural history of Northeastern Brazil. Description of the habits of common animals, together with zoogeographical records are useful for the modern zoologist.

This paper brings together the recorded information on the mammals of Maranhão, as described and depicted by two French friars and one Portuguese, who lived in the island during the first half of the XVIth Century.
\end{abstract}

\section{INTRODUÇÃO}

O estudo dos códices e crônicas da América dos séculos XVI e XVII vale não apenas como contribuição à história, mas à zoogeografia também. A publicação de antigos manuscritos que permaneceram durante séculos, inéditos ou desaparecidos permite-nos descobrir, nas descrições, desenhos e entrelinhas das narrativas singelas, por vezes fantasiosas e quase infantis, contribuições pioneiras e menções a fatos ou fenômenos de interesse para a ciência e sua historiografia. Para biogeógrafos, ecólogos e sistematas, essas obras encerram valor prático de importância imediata, ao registrarem dados sobre distribuição geográfica primitiva de elementos da flora e fauna, rotas de dispersão, abundância ou raridade de espécies e alterações no tipo de cobertura vegetal ou paisagem.

Alguns autores entendem a história da ciência à semelhança daqueles para quem a evolução biológica é um processo teleológico de aperfeiçoamento progressivo a linear (the great chain of beings). $\mathrm{O}$ relato histórico seria a busca da verdade, que teria início nas trevas da ignorância primitiva e terminaria à luz dos conhecimentos atuais (the great chain of events). Uns e outros estão errados. Evolução e história são processos complexos de tentativas e erros, de extinção e sobrevivência ao longo do tempo, sem rota predeterminada nem objetivos a atingir. Nem todo conhecimento

1. Bolsista do CNPq. Escola Nacional de Saúde Pública (FIOCRUZ). Caixa Postal 926. 21041, Rio de Janeiro - RJ, Brasil. 
antigo é primitivo ou profético, nem toda teoria traz o germe das concepções modernas.

Os primeiros cronistas das terras brasileiras produziram relatórios em que aparecem reunidos, observações e testemunhos pessoais, ao lado de tudo quanto conseguiram recolher de informantes nativos ou europeus residentes, e compilar de cartas ou documentos contemporâneos. Sua preocupação era a de elucidar a geografia, descrever o clima, retratar os habitantes, as doenças, as produções naturais.

Rodolfo Garcia, na introdução ao relatório de Abbéville $(1945,1975)$ mostra-se admirado da "Maravilha como, no curto espaço de sua estada no Maranhão, Claude d'Abbéville pôde adquirir o imenso cabedal de conhecimentos que transmitiu aos pósteros". Jaime Walter, comentador da obra de Frei Cristovão de Lisboa, ressalta, além das referências à França, o encontro de "uma ou outra palavra escrita à moda francesa (...). Isto faz-nos pensar que o colaborador de Frei Cristovão tenha sido um português que contactou bastante com os franceses, tendo-lhes fornecido muitos elementos que, mais tarde, veio dispor em pról do célebre custódio." A identidade de muitos desses informantes permanece, entretanto, desconhecida.

Do empenho criterioso em distinguir fatos de lendas, em verificar a autenticidade dos relatos, em descontar os arroubos da imaginação excitada pelas novidades de um novo mundo - que ainda hoje colorem as descriçőes dos turistas e dos agentes de viagem - depende a utilidade dos registros antigos para o cientista moderno. Certas crendices e lendas zoológicas sobrevivem ao passar do tempo e foram transportadas da europa medieval para o continente americano, como a que credita os ouriços de lá e os coandus daquí com a esperteza de rolarem sobre frutos caídos ao solo, empalando-os nos espinhos para transportá-los a seus abrigos, ou com a faculdade de lançar os acúleos sobre um predador.

Por outro lado, o conhecimento empírico e minucioso dos hábitos dos animais, das épocas de reprodução, dos ritmos de atividade, indispensáveis ao pescador e ao caçador, este é transmitido de uma geração a outra e incrementado na rotina venatória.

Mudam certos fundamentos da taxonomia, mas podem permanecer válidos sistemas de classificação. Altera-se a visão do sistemata, porém as informações disponíveis ao homem do campo não se modificam com o tempo. E são elas que vamos buscar nas crônicas, com o fim de confirmar a ocorrência de espécies em regiões de onde desapareceram nos últimos séculos e de avaliar a acuidade de observação dos cronistas do passado.

A fauna do Maranhão é mal conhecida e devemos a SNETHLAGE (1926) e a VIEIRA (1957) os únicos trabalhos de carácter taxonômico mais recentes. 


\section{A França Equinocial}

Conta-nos Abbéville que, em 1594, um capitão francês, Jacques Riffault, partiu com três navios para explorar o litoral norte do Brasil, fiado na amizade travada com um nativo da região. Perdeu dois de seus barcos nos baixios de Santa Ana e parte da tripulação excedente foi deixada em terra. Destes, quatorze foram aprisionados por Feliciano Coelho, Capitão Mor da Paraíba, entre os quais Charles des Vaux, amigo dos índios maranhenses. Ganhando a liberdade e retornando à França, tudo fez des Vaux para divulgar as riquezas da região e incentivar sua colonização pelos franceses.

Em 1604, Daniel de la Touche, senhor de La Ravardière, partiu da França para o Maranhão a mando de Henrique IV, levando à bordo des Vaux. Sua expedição durou seis meses. A morte do rei fez adiar os planos de instalação definitiva de uma colônia na região, o que só aconteceria no reinado de Luis XIII, sob a regência de Maria de Médicis.

Em 19 de março de 1612, La Ravardière partiu novamente da Europa com a missão de estabelecer uma colônia ao sul da linha equinocial, com a extenção de 50 léguas para cada lado do forte que deveria construir. Quatro missionários capuchinhos, chefiados por Yves d'Evreux, integravam a expedição que aportou no Maranhão em 29 de julho do mesmo ano.

Os franceses seriam expulsos em 1615. Na época, Portugal e Espanha estavam reunidos sob o cetro de Felipe II.

Dois dos capuchinhos deixaram crônicas escritas. Claude d'Abbéville, que permaneceu no Maranhão por quatro meses e Yves d'Evreux que ficou dois anos.

Após a saída dos franceses, Portugal e Espanha trataram de enviar uma missão à ilha de São Luis, integrada pelo também capuchinho Frei Cristóvão de Lisboa, o qual foi encarregado de fundar a custódia do Maranhão e Grão-Pará, que incluia as terras dos atuais estados do Ceará, Piauí, Amazonas e Maranhão. Permaneceu lá por onze anos, tendo chegado ao Brasil em 2 de maio e aportado na ilha em 16 de agosto de 1624. Regressaria a Portugal em 1635.

\section{Claude d'Abbéville}

Segundo MELLO LEITÃO (1937), “São ainda os livros de Claudio d'Abbéville e Ivo d'Evreux as melhores achegas para a zoogeografia dessa região entre a Amazonia e o sertão, essa faixa de transição da Hiléia para a caatinga".

A obra de Abbéville é a mais completa, tendo Yves d' Evreux se limitado a acrescentar algumas informaçöes que considerou importantes.

No presente trabalho foi utilizada a edição de 1975, facsímile da de 1945. 
Ocupado com os deveres religiosos e preocupado com a sociologia indígena, Abbéville deve ter encontrado bons informantes entre portugueses e nativos que lhe forneciam dados sobre a fauna e a flora. Certamente os quatro meses que passou no Brasil não teriam sido suficientes para que se tornasse fluente na língua geral, nem observado tudo quanto registrou, e é possível que alguns portugueses, versados nessas questỏes, o tenham auxiliado, bem como a Cristóvão de Lisboa.

\section{Mamíferos na Obra de Abbéville}

Abbéville (p.162) nota que: “Não temos entre nós todas as espécies de animais que eles têm, nem eles possuem nada que se assemelhe aos nossos, a não ser com grande diferença, (...). Possuem entretanto muitos veados, corças, javalís não inteiramente iguais aos nossos".

Em face da riqueza da fauna e da flora, decide contentar-se em tratar de algumas espécies em particular, o que faz agregando informaçōes verídicas a outras, duvidosas e algumas indubitavelmente míticas ou legendárias.

Assim, diz que o tapir serve de cargueiro "Quando agarrado".

Depois de discutir a influência dos signos do Zodíaco sobre a fauna, passa a descrever os animais que povoam os ares, a terra e as águas. Entre os primeiros inclui os quirópteros (p.189): “E há os andeirá, morcegos muito parecidos com os nossos, porém maiores e que gritam muito mais alto e de um modo horrível". Não distingue espécies, mas descreve hábitos de hematofagia e nota a preferência pela mordida "na ponta do dedo grande", a insensibilidade do ferimento e a hemorragia abundante que dele resulta. Afirma que os índios não os comem.

Entre os peixes marinhos inclui o "uarauá, maior e mais encorpado do que a maioria dos bois". Elogia sua carne saborosa e a sopa que dela se faz, tão boa quanto a da carne de gado. Alimenta-se de ervas e folhas de "aparituriers", encontrados à beira mar (mangue).

Dentre as espécies terrestres, algumas merecem comentários especiais.

A descrição do tamanduá-bandeira exagera seu porte, comparando ao do cavalo. Os índios velhos o comem, mas "recusam-se os moços a fazer o mesmo, alegando que, se comerem a carne deste animal que se alimenta de formigas, ficariam débeis e sem coragem na guerra".

As antas são comparadas às vacas e diz encontrarem-se nelas a “pedra-bazar" ou bezoar.

Descreve uma variedade de tatus, sendo importante registrar a presença de duas espécies de maior porte no Maranhão. Por sua vez, tatuuainchum é de identidade duvidosa. Seu nome não consta dos vocabulários tupis, podendo ser uma corruptela de uaia-chué (cauda minúscula).

$\mathrm{O}$ quati é considerado um bom manjar.

Dos roedores, as descrições da paca, cutia e tapiti são boas. Punaré, mocó e sauiá (saviá) podem ser identificados pelo nome tupi, o que as breves descrições confirmam.

A descrição da suçuarana erra ao mencionar a pele malhada. 
As preguiças causariam espanto e são descritas como "animal monstruoso, de cabeça redonda, semelhante à do homem” (...).

Os primatas mereceram atenção especial. Guaribas são facilmente reconhecíveis. Os cai-açu, levados freqüentemente para a Europa, seriam Cebus apella.

Os cai-ou "completamente pretos: têm uma barba comprida de mais de quatro dedos e até meio pé", foram corretamente identificados por MELLO LEITÃO (1937) como cuxiús. Ocorrem na região do Tocantins.

Cai-mirim, com o pêlo amarelo misturado de outras cores é também Cebus appela que apresenta grande variação individual no colorido. Tamari designa, na amazônia, duas espécies do gênero Saguinus. Mas a descrição de Abbéville, "pequeníssimos e também de diversas cores" cabe melhor às espécies de Callithrix. $\mathrm{O}$ mesmo acontece com os mariquinas.

O nome jupará é dado a um carnívoro procionídeo do gênero Potos, mas aqui parece haver confusão com os macacos-da-noite, primatas do gênero Aotus. Tanto no nordeste como na amazônia, os juparás são confundidos com macacos e chamados popularmente de "macacos-dameia-noite".

Os saguís de pêlo prateado são Callithrix argentata do Pará. Deve ser lembrado que os primatas sempre figuraram entre os animais de estimação preferidos e é possível que Abbéville tenha visto espécies amazônicas na ilha de São Luis.

Entre os animais marinhos (ou aquáticos) menciona a capivara.

\section{Relação das espécies citadas}

\begin{tabular}{|c|c|c|}
\hline Abbéville & R.Garcia(notas) & Nome científico \\
\hline Andeiră & Andirá & Desmodus rotundus (E.Geoffroy, 1810) \\
\hline Uauará & Guaragå & Trichechus manatus Linnaeus, 1758 \\
\hline Saçu-apar & Suaçu-apará & Edocerus dichotumus (Illiger, 1815) \\
\hline Suaçu & Suaçu & Mazama sp. \\
\hline Taiaçu & Taiaçu & Tayassu pecari (Link, 1795) \\
\hline Taiaçu-etê & Taiaçu-etê & Tayassu tajacu (Linnaeus. 1758) \\
\hline Coandu & Cuandu & Coendou prehensilis (Linnaeus, 1758) \\
\hline Tamanduå & Tamanduá & Myrmecophaga tridactyla Linnaeus. 1758 \\
\hline Tapiine-etê & Tapira-etê & Tapirus terrestris (Linnaeus, 1758) \\
\hline Taturaçu & & Pridontes maximus Kerr, 1792 \\
\hline Tatuíaçu & & Cabassous unicinctus (Linnaeus, 1758) \\
\hline Taturetê & & Dasypus novemcinctus Linnaeus, 1758 \\
\hline Taturpep & & Euphractus sexcinctus (Linnaeus, 1758) \\
\hline Taturapar & & Tolypeutes trincinctus (Linnaeus, 1758) \\
\hline Tatu-uamchum & & ? Cabassous tatouay (Desmarest, 1804) \\
\hline Tatu-mirim & & ? Dasypus septemcinctus Linnaeus, 1758 \\
\hline Coati & Quati & Nasua nasua (Linnaeus, 1758) \\
\hline Paca & & Agouti paca (Linnaeus, 1766) \\
\hline Aguti & & Dasyprocta primnolopha Wagler, 1831 \\
\hline Tapiti & Tapiti & Sylvilagus brasiliensis (Linnaeus, 1758) \\
\hline
\end{tabular}




$\begin{array}{ll}\text { Ponaré } & \text { Punaré } \\ \text { Amocó } & \text { Mocó } \\ \text { Sauiá } & \text { Sauiå } \\ \text { Jauarê } & \text { Jaguar } \\ \text { Suaçuarã } & \text { Suaçurana } \\ \text { Margaiå } & \text { Maracajå } \\ \text { Unau } & \text { Unaf } \\ \text { Unaưaçu } & \text { Unaf-açu } \\ \text { Uarive } & \text { Guariba } \\ \text { Cai-açu } & \text { Caf } \\ \text { Cai-ou } & \\ \text { Cai-mirim,sapajou } & \\ \text { Tamari } & \\ \text { Mariquinas } & \\ \text { Jupara } & \\ \text { Saguis } & \end{array}$

Trichomys apereoides Lund, 1839

Kerodon rupestris (Wied, 1820)

? Cavia sp.

Panthera onca (Linnaeus, 1758)

Felis concolor Linnaeus, 1771

Felis pardalis Linnaeus, 1758

Bradypus tricadtylus Linnaeus, 1758

Choloepus didactylus (Linnaeus, 1758)

Alouatta belzebul (Linnaeus, 1766)

Cebus apella (Linnaeus, 1758)

Chiropotes satanas (Hoffmannsegg, 1807)

? Cebus apella (Linnaeus, 1758)

? Saguinus tamarin (Link, 1795)

Callithrix sp.

? Potos flavus (Schreber, 1774) ou Aotus sp.

Callithrix argentata (Linnaeus, 1771)

Callithrix jacchus (Linnaeus, 1758)

\section{Yves d'Evreux}

Olivério Pinto considera d'Evreux "De assombrosa credulidade e, na maioria das vezes, evidentemente exagerado, nenhum empenho faz d'Evreux para separar o fabuloso do verdadeiro quando (...) fala das aves maranhenses".

A preocupação primordial do superior da missão religiosa era com os selvagens, seus costumes, organização familiar, crenças e com a sua catequese. Críticas faz, por vezes, com o "fim [de] mostrar a cegueira das almas captivas pelo espírito immundo, que não se descuida perde-las por meio de suas traças". Entretanto, não esconde a admiração por certos hábitos e comportamentos dos nativos.

D’Evreux deixa claro que suas observações sobre a natureza foram registradas com a finalidade de completar as de Abbéville e diz que "somente acrescentarei o que mais do que elle soube por experiência, pois eu estive no Maranhão dois annos completos e elle apenas quatro mezes". Ainda assim, o trabalho de coligir dados de Abbéville foi notável e as observações de d'Evreux são particularmente ingênuas. Durante sua estada, La Ravardière viajou ao Mearim e ao Pará.

Neste trabalho foi utilizada a edição de 1929.

\section{Mamíferos na obra de Yves d'Evreux}

O capuchinho teve, como os demais cronistas, a atenção despertada pelo peixe-boi, cuja pesca era feita a 30 ou 40 léguas distante da ilha: "estes peixes tem a testa como os bois, porém sem cornos, duas patas adiante debaixo das mamas, párem os filhos como as vaccas, nutrem-nos 
com seo leite, mas a cria tem a propriedade notável de abraçar a mãe pelas costas com suas patinhas, e nunca os deixa embora mortas, pelo que alguns são agarrados vivos, e assim trazidos para a ilha: são muito delicados".

D’Evreux menciona corretamente o hábito dos indígenas de fazerem incisões no próprio corpo "o que praticam por meio de um dente de Cutia, muito agudo..."

Diz que os nativos atribuem a origem do ambar gris às baleias (no que estavam mais certos que os franceses), porém consideram-no como sendo seu excremento.

Descreve uma curiosa caçada aos ratos do mato, em que se fazia uma batida em direção a uma série de fojos. Os nativos rejeitavam os ratos caseiros "que infestam os navios e fogem para a terra tão logo aportam". Menciona que são mais abundantes nas aldeias localizadas à beira-mar. Preferem os "do mato" aos javalís e viados".

Menciona a predação "de formigas" pelos tamanduás: "As formigas do Maranhão têm dois inimigos encarniçados, especialmente estas aladas: Um- certa espécie de cães selvagens com pello de lobo, fedorentos o mais que é possível, focinho e língua muito aguda, e que procura o formigueiro para alimentar-se (...)".

D’Evreux discorre longamente sobre os grilos que nascem "da corrupção". Dentre seus inimigos cita "certos macaquinhos amarellos e verdes a quem chamam os selvagens Sapaius, vivos e ágeis como um pássaro; caçam com uma das mãos e na outra guardam os grillos". A referência pode ser a Saimiri, do Pará.

Dedicou um capítulo às onças e macacos. "A onça é o animal mais furioso do Brasil e é do tamanho dos galgos da Europa". A longa descrição de seus hábitos sociais e comportamento é factual e acurada, sem os exageros e mitos que ainda hoje se incorporam a muitos relatos semi-populares. Menciona, contudo, que "Existem onças marinhas, como já disse quando fallei do Meary, tendo a parte anterior igual a da terra e a posterior similhante a cauda de um peixe". Pode-se reconhecer aqui a ariranha.

As descrições que faz dos primatas são mais superficiais, menos precisas e pouco verídicas. A primeira espécie, "uns grandes, fortes, barbados e de sexo bem distinto" pode ser Chiropotes satanas ou Alouatta belzebul. Duas histórias que registra, ainda hoje, encontram ouvintes crédulos: a de que respondem a um ataque lançando objetos com pontaria certeira e a de que podem manter relações sexuais com mulheres. A primeira lenda decorre da observação mesclada com a imaginação, de um comportamento aleatório, quando partem um galho de árvore e o lançam para baixo sem direção. A segunda revela elementos comuns com os mitos do boto e do vento, da amazônia, e serve de desculpa, socialmente aceitável, para aventuras socialmente condenáveis.

"Há outros barbados, mais pequenos, que trazem mamas nos seios, e sexo bem visível em lugar próprio". Provavelmente, Alouatta.

"Os triviaes são quasi que similhantes em sexo e nem merecem 
descripção alguma". Deixando de lado a preocupação constante do capuchinho com o sexo, pode-se admitir que se refere a Cebus, abundantes e frequientemente levados à Europa. A descrição do comportamento dos bandos que surpreenderam na floresta e nos bebedouros naturais permite reconhecer os micos, inclusive no hábito de consumirem crustáceos.

\section{Relação das espécies citadas}

$\begin{array}{ll}\text { Peixe boi } & \text { Trichechus manatus Linnaeus, 1758 } \\ \text { Cutia } & \text { Dasyprocta primnolopha Wagler, 1831 } \\ \text { Tamanduá } & \text { Myrmecophaga tridactyla Linnaeus, 1758 } \\ \text { Onça } & \text { Panthera onca (Linnaeus, 1758) } \\ \text { Ariranha } & \text { Pteronura brasiliensis (Zimmermann, 1780) } \\ \text { Cuxiu } & \text { Chiropotes satanas (Hoffmannsegg, 1807) } \\ \text { Bugio } & \text { Alouatta belzebul (Linnaeus, 1766) } \\ \text { Mico } & \text { Cebus apella (Linnaeus, 1758) } \\ \text { Sapaius } & \text { Saimiri sciureus (Linnaeus, 1758) }\end{array}$

\section{Frei Cristóvão de Lisboa}

O capuchinho português legou-nos um códice, escrito provavelmente entre 1624 e 1627, publicado pela primeira vez em 1967 pelo Arquivo Histórico Ultramarino e Centro de Estudos Históricos Ultramarinos, de Lisboa.

É importante a sua leitura em conjunto com a dos frades franceses que, alem de contemporâneos, possivelmente compartilharam os mesmos informantes.

Segundo Walter "É possível que tenha sido recolhido pelo confrade a que se referiu em carta, o qual escreveria o relato feito por algum português discorrendo sobre as espécies desenhadas e outras, que the surgiram na memória". Teria sido um europeu, profundamente conhecedor da regiäo e da língua tupi, e que, além disso, teve contato com os franceses.

No desempenho de sua missão, frei Cristóvão de Lisboa viajou pelo interior do nordeste brasileiro e chegou a Belém, no Pará.

O manuscrito inclui desenho de animais e plantas, com a anotação "estampa" daqueles destinados à publicação, que só agora veio à luz; comentários sobre as espécies ilustradas e um índice, sendo as espécies do Pará listadas em separado. Da maioria dos mamíferos não consta descrição.

A edição traz um estudo minucioso de Jaime Walter, que recuperou a biografia do frade e analizou sua obra. Ao contrário da de seus correligionários franceses, a obra de frei Cristóvão de Lisboa permite a identificação segura dos mamíferos, pelos detalhes registrados nas ilustrações, as mais antigas que retratam a fauna maranhense. 


\section{Mamíferos na obra de Frei Cristóvão de Lisboa}

Uma vez que o tupi não era originalmente escrito, tratariam os jesuítas de prepararem as primeiras cartilhas com o fim de criarem uma língua geral. Por esta razão, verificam-se discrepâncias ligeiras na grafia do Índice, das descriçöes e estampas. Distinguem-se, no texto e nos títulos, dois tipos de letra, o que também explica as diferentes transcrições fonéticas dos nomes das espécies. O desenhista mostrou cuidado especial com os detalhes dos pés, mãos e unhas dos animais.

Apenas o peixe-boi e o morcego possuem texto descritivo, por estarem colocados, respectivamente, entre os peixes e as aves.

Os comentários que se seguem obedecem à sequêencia e à numeração original das estampas ou fólios.

\section{Fol.1. Gara, Peixe boy, guaragua}

Entra no índice como "Gara, peixe boi"; "Guaragua, peixe boy"; e como "Peixe boi". No fólio 1, dois desenhos representam o animal em vista dorsal e ventral. A descrição encontra-se no fólio 164.

Jaime Walter valendo-se das notas inéditas de Fernando Frade, tece um longo comentário, no qual as referências ao peixe-boi americano e ao dugong das costas da África, Ásia e Austrália são confundidas. No velho Mundo, sirênios deram lugar à lenda das sereias e, no Brasil, à da ipupiara, monstro mítico figurado por Gandavo (1575) em luta com Baltazar Ferreira e descrito por Jean de Léry (1578) e por Fernão Cardim.

O padre José de Anchieta, em carta escrita em 1560, descreve o peixe-boi, que diz ser freqüente na Capitania do Espírito Santo. Gabriel Soares de Souza assinala sua presença na Bahia em 1587 e Gandavo, na Província de Santa Cruz, atual Rio de Janeiro.

$\mathrm{O}$ príncipe Maximiliano de Wied Neuwied mencionou-o tanto em sua viagem (1820) como no volume dedicado à descrição dos mamíferos (1826): “Em Villa Nova, hoje Nova Almeida, Espírito Santo, ouvimos falar muito de um animal marinho nunca visto antes aí, e que uns índios mataram na praia havia pouco, a tiros de mosquete. Era grande e dizia se possuir pés parecidos com mãos humanas. Estraira-se dele grande quantidade de gordura. A cabeça e os pés foram enviados ao governador. Todas as nossas tentativas para obter informações pormenorizadas sôbre êsse animal foram inúteis, mesmo porque partiram e cozinharam o esqueleto, e em parte o enterraram. De tudo o que soubemos, entretanto, parece que se tratava de uma "phoca" ou "manati". (...) No Rio São Mateus... encontra-se um animal raro, que até agora só foi encontrado em muito poucos rios da costa oriental. Trata-se do manati ou "peixe-boi" dos portugueses. A história natural desse curioso bicho é ainda obscura em muitos pontos; é bastante freqüente no rio em questão, dizendo-se que algumas vezes sai para o mar e se dirige, ao longo do litoral, para outros rios; assim, por exemplo, já foi capturado no Alcobaça. Em S.Mateus, o refúgio preferido do manati é uma "lagoa" densamente coberta de caniços e gramíneas outras. Não é sem dificuldade que pode ser 
caçado, num pequeno barco, rema atenta e silenciosamente entre os caniços e o capinzal; se vê o bicho com o dorso acima dágua, como acontece habitualmente quando está pastando, aproxima-se com cautela e arremessa-lhe o arpão ligado a uma corda. O manti fornece grande quantidade de gordura e a carne é apreciada. $\mathrm{O}$ osso timpânico do ouvido é tido como remédio poderoso pelo povo ignorante, e comprado a alto preço. Embora fizesse, constantemente, grandes promessas, durante minha estadia de três a quatro meses nessas paragens, com o intuito de obter um desses animais, falharam minhas esperanças, e fui obrigado a contentar-me em ver, ao voltar do Brasil, os manatis empalhados do gabinete de História Natural de Lisboa".

Wied assinala seu limite sul como sendo o Rio de Janeiro.

Os exemplares que viu em Lisboa foram coletados por Alexandre Rodrigues Ferreira, o primeiro a enviá-los à Europa.

Olivério Pinto, anotador da tradução brasileira do relato da viagem de Wied, acrescentou, em nota, o seguinte: "Sua existência ainda em nossos dias no alto do Rio Doce foi-me verbalmente asseverada por Pinto da Fonseca, bastante conhecedor da fauna daquela região".

Duas espécies recentes existem nas Américas: Trichecus inunguis (Pelzeln, 1883), das bacias do Amazonas e Orenoco e Trichecus manatus Linnaeus, 1758, encontrado desde o golfo do México e Antilhas, a embocadura dos rios da América do Sul, e que Colombo descreveu do Rio do Oro, em 1493.

\section{Fol.4. Pira Iaquara}

Listado no índice como Pira iaguara. Frei Lisboa figurou-o no fólio 4 e descreveu-o no fólio 175, entre os peixes do Pará: “É espécie de porco marinho; no Sabor é como porco, principalmente o fígado, gera como animal [trecho riscado], tem, as partes genitais como o porco e tem nove palmos de comprido, e grosso nesta proporção; faz-se do rabo manteiga; as fêmeas parem como os animais; tem um buraco acima do nariz por onde respira e lança água".

$\mathrm{O}$ boto vermelho, reconhecível no desenho, ocupa lugar de destaque no folclore amazônico. É a uiara dos indígenas e caboclos, sedutor de donzelas, cujo olho, posto a secar, constitui poderoso talismã para o amor; animal que persegue e vira canoas em que viajam moças virgens, que sai à terra disfarçado em rapaz, com os pés fendidos de cabra. Raimundo Moraes, Câmara Cascudo e Gastão Cruls registraram as numerosas lendas que o cercam.

É curiosa a referência a seu uso como alimento. Na Amazônia nem esta espécie Inia geoffroiensis (Blainville, 1817) nem o tucuxi ou boto preto, Sotalia fluviatilis (Gervais e Deville, 1863) são perseguidos ou comidos. Especialmente o fígado dos mamíferos aquáticos é impróprio para consumo, podendo provocar hipervitaminose A e causar um sério acidente. William $\mathrm{H}$. Burt descreveu o que aconteceu à tripulação do navio em que viajava, no ártico, e qual, inadvertidamente, comeu fígado de urso polar. Esse autor, mamalogista famoso, somente se lembrou do perigo após o jantar e anotou os sintomas que incapacitaram os homens 
Vol. 6(3), 1989

por 48 horas.

Mac Creagh, autor de um dos mais notáveis relatos de viagem já publicados, descreve o envenenamento de um dos membros da desastrada expedição, atribuida ao óleo de figado do "botu fish", ocorrido no Amazonas.

\section{Fol.62. Capivara}

Alvaro Mones, ao resumir a história taxonômica dos Hydrochoeridae, reconheceu: "La mås antigua ilustración que conocemos de um "carpincho", corresponde a la representada en la lámina 62 (parte superior) de la obra de Frei Cristóvão de Lisboa (....)".

O desenho não foi selecionado para publicação, pois não traz a designação de "estampa". A face do animal lembra mais a de uma anta.

\section{Fol.62. Tamandoa-i}

Os dois dedos na mão e cauda não identificam Cyclops didactylus. A årea de distribuição da espécie é disjunta e abrange parte da Amazônia e parte da mata Atlântica, no nordeste brasileiro, separadas pela região das caatingas. Como não há texto referente aos mamíferos silvestres, não se conhece a procedência do animal desenhado.

\section{Fol.63. Paca}

O desenho representa uma Cotia, Dasyprocta sp., havendo confusão evidente com o nome vulgar. Veja-se o fólio 65.

\section{Fol.63. Quati}

Rinário e cauda são característicos de Nasua nasua, mas o desenho parece-se com o do guaxinim (fólio 69).

\section{Fol.64. Veado ou Corso}

Guaçu é o nome tupi de todos os cervídeos. A figura mostra uma fêmea do que pode ser o veado-campeiro (Blastocerus bezoarticus). Como no fólio seguinte há o desenho de um casal de cervos (Edocerus dichotomus), é provável que esta seja um suaçu-etê (bezoarticus).

\section{Fol.64. Veado}

A ornamenta do macho é típica do cervo-do-pantanal (E. dichotomus), o que indica que sua distribuição geográfica era muito mais extensa que a atual. O desenho não mostra as pernas pretas, que são características do animal.

\section{Fol.65. Tatu}

$\mathrm{O}$ escudo cefálico e as bandas articuladas identificam a espécie mais comum e mais apreciada como alimento, o tatu-galinha.

\section{Fol.65. Paca}

Aqui, sim, o desenho representa Agouti paca com a pelagem manchada que lhe é característica. 
Fol.66. Tambu

Pouco legível, na letra que não é de Cristóvão de Lisboa, pode-se perceber "ou Moucoure" - como um francês escreveria o nome local "mucurra", ainda hoje utilizado para o gambá.

Fol.66. Sauoya, Coelho que tem feição de Rato

O nome tupi soiá ou çavia é utilizado para vários equimídeos. O desenho representa um rato-de-espinho, e a espécie mais comum, que mereceria registro é o punaré, muito apreciada como alimento e à qual Abbéville também faz referência.

\section{Fol.67. Sapagiu}

O nome utilizado é curioso, pois sapajou, em francês, designa os macacos de genêro Cebus. A figura mostra um casal de veados do gênero Mazama.

\section{Fol.67. Maracava}

Gato-do-mato, provavelmente Felis pardalis, a jaguatirica.

\section{Fol.68. Bugio, machacha}

A figura representa Saimiri sp. e lembra a de Alexandre Rodrigues Ferreira do "boca preta", da amazônia.

\section{Fol.68. Guariba}

A cauda anelada, os dedos longos e o manto sugerem Saguinus tamarim, do Pará e não um Alouatta, aos quais o nome comum se aplica.

\section{Fol.68. Taiasu}

No índice, taiasu, porco. Visível a glândula que se encontra no dorso, a qual alguns cronistas identificaram como sendo o umbigo. A ausência da mancha branca gular identifica o caitetu.

\section{Fol.69. Uuasini}

O desenho lembra o do quati, mas as mãos são características do guaxinim ou mão-pelada.

\section{Fol.69. Tamanduá}

A cauda é típica do tamanduá bandeira, a espécie maior.

\section{Fol.71. Prigui sa}

Facilmente reconhecível, um macho de Bradypus tridactylus.

\section{Fol.107. Amdura}

Aparece no índice como Andura e é descrito no fólio 194 entre os "Pássaros que estão pelos matos e campinas". Menciona a preferência pela mordida no dedo grande do pé (hálux). A descrição é correta, menos onde se diz "levam um bocado de carne". A figura é de um 
Vol. 6(3), 1989

morcego sem folha nasal, sem cauda e com uropatágio reduzido; polegares muito desenvolvidos, o que concorda com a aparência de Desmodus.

\section{Relação das espécies citadas}

Folios

Gara, guaragua, peixe boy

Pira iaguara

Capivara

Tamandua-i

Paca

Quati

Veado ou corso

Soasu, veado

Tatu

Paca

Tambu

Sauoya

Sapagiou

Maracaya

Bug io machacha

Guariba

Porco taiasu

Quasini

Tamandua

Priguisa

Amdura, andura

\section{Nomes cientfficos}

Trichechus manatus Linnaeus, 1758

Inia geoffroienses (Blainville, 1817)

Hidrochaeris hydrochaeris (Linnaeus, 1766)

Cyclopes didactylus (Linnaeus, 1758)

Dasyprocta primnolopha Wagler, 1831

Nasua nasua (Linnaeus, 1766)

Blastocerus bezoarticus (Linnaeus, 1758)

Edocerus dichotomus (Illiger, 1815)

Dasypus novemcinctus (Linnaeus. 1758)

Agouti paca (Linnaeus, 1766)

Didelphis sp.

Trichomys apereoides Lund, 1839

Mazama sp.

Felis pardalis Linnaeus, 1758

Saimiri sciureus (Linnaeus, 1758)

? Saguinus tamarin (Link, 1795)

Tayassu pecari (Link, 1795)

Procyon cancrivorous Brogniart, 1792

Myrmecophaga tridactyla Linnaeus, 1758

Bradypus tridactylus Linnaeus, 1758

Desmodus rotundus (E.Geoffroy, 1810) 

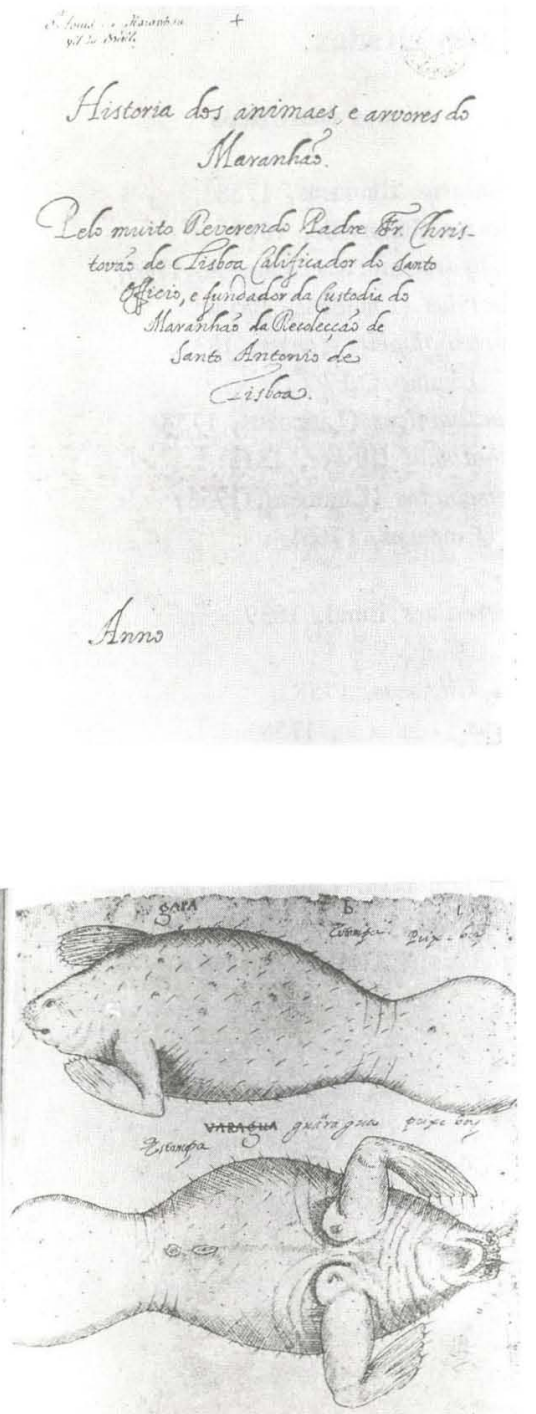

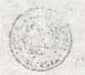
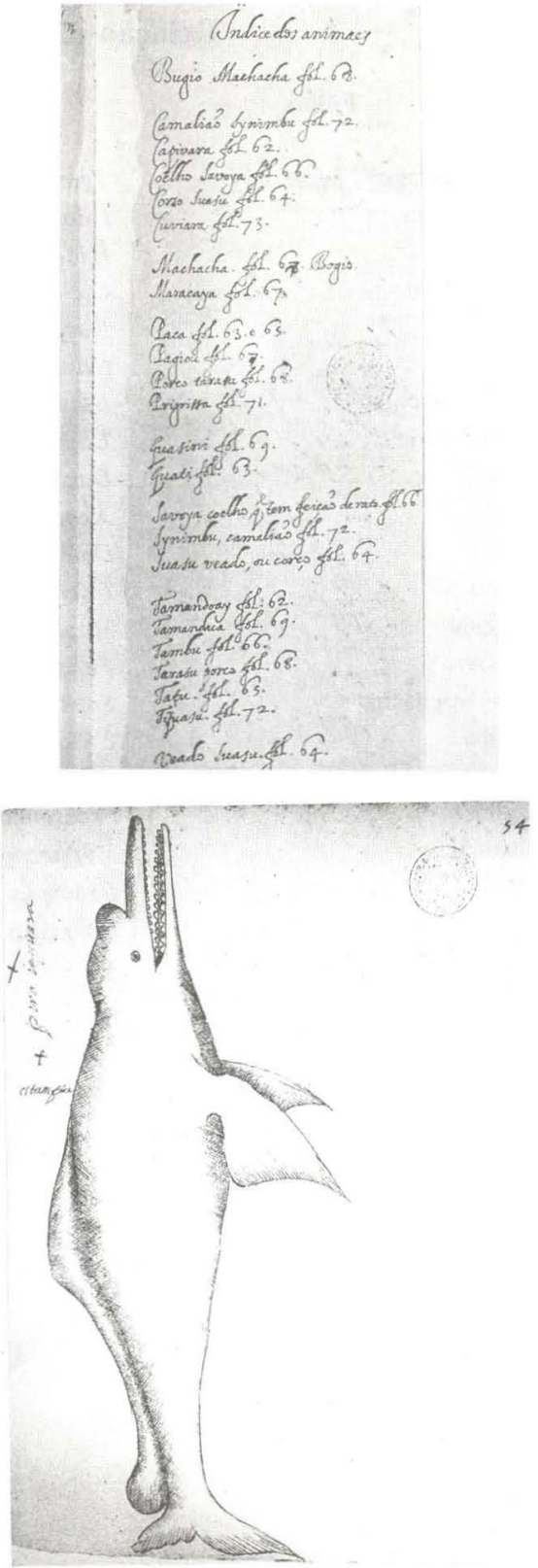
Vol. 6(3), 1989
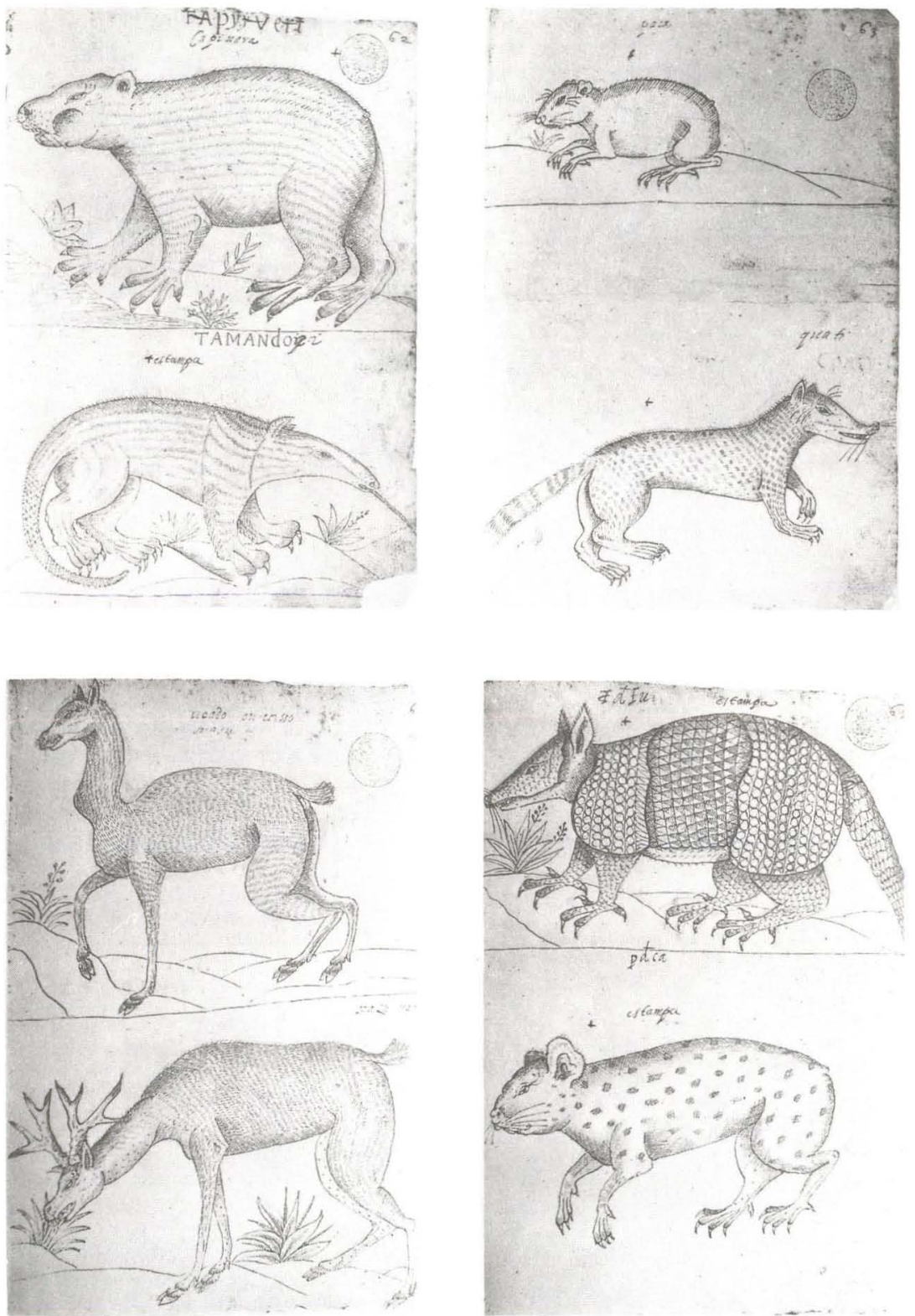

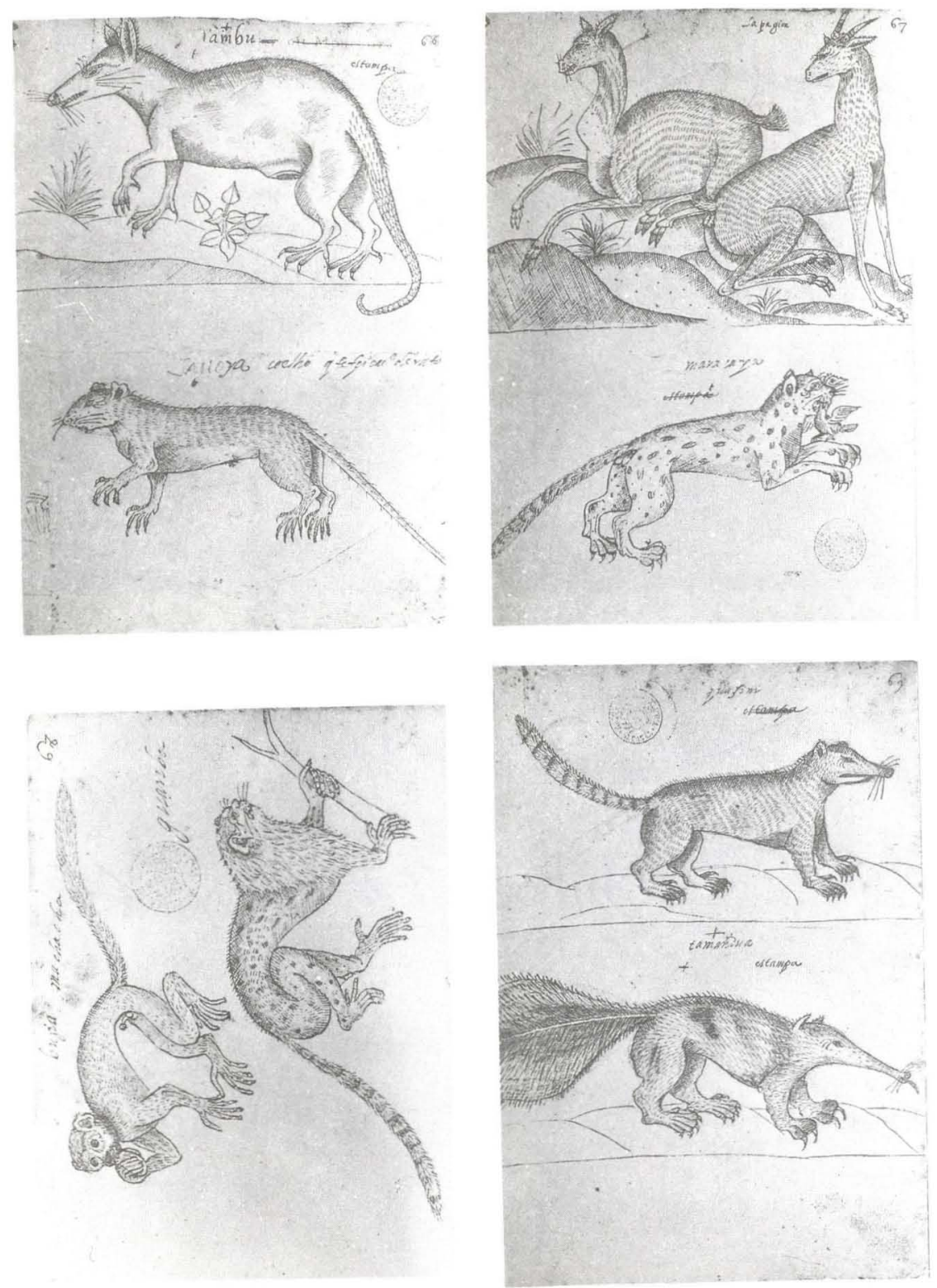
Vol. 6(3), 1989
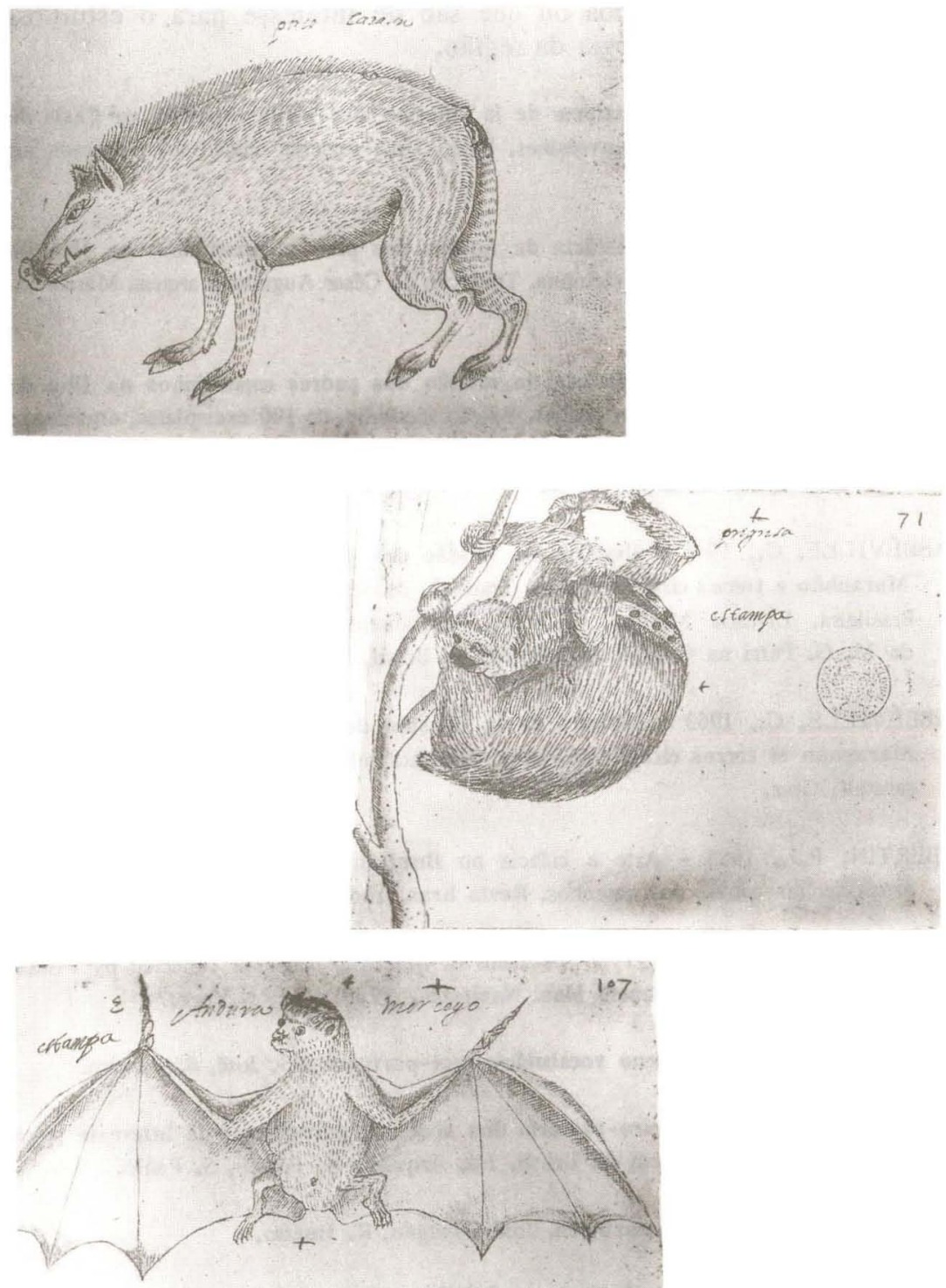

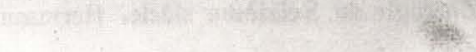




\section{BIBLIOGR AFIA}

Além dos trabalhos citados no texto, encontram-se relacionados outros que foram consultados ou que são de interesse para o estudioso da história da mastozoologia da região.

D’ABBÉVILle, C., 1614 - Historie de la mission des pères capucins en l'Isle de Maragnan et terres circonvoisines. Paris. Uma segunda ediçäo foi publicada no mesmo ano.

D’ABBÉVILLE, C., 1876 - História da missão dos padres capuchinhos na Itha do Maranhäo e terras circunvizinhas. Traduçāo de César Augusto Marques. Maranhão. Reeditado em 1928

D’ABBÉVILLE, C., 1922 - História da missão dos padres capuchinhos na Ilha do Maranhão e terras circunvizinhas. Edição facsímile, de 100 exemplares, organizada por Antonio Prado, com prefácio e necrológio de Capistrano de Abreu e glossário de termos tupi de Rodolfo Garcia.

D’ABBÉVILLE, C., 1945 - Histớria da missão dos padres capuchinhos na Ilha do Maranhäo e tarras circunvizinhas. Tradução de Sérgio Milliet. Biblioteca Histórica Brasileira, Livraria Martins, S. Paulo. Reproduzido em facsímile, com introdução de M. G. Ferri na Coleção Reconquista do Brasil, USP/Itatiaia, S. Paulo, 1975.

D’ABBÉVILLE, C., 1963 - Histoire de la mission des pères capucins en l'Isle de Maragnan et terres circonvoisines, Edição facsfmile, Akademishe Druck-u, Verlagsanstalt, Graz.

ALBERTIN, P.J., 1985 - Arte e ciência no Brasil holandês. Theatrirerum naturali brasiliae: um estudo dos desenhos. Revta bras. zool., 3(5): 249-326, S. Paulo.

AVILA-PIRES, F.D., 1965 - Type specimens of Braziliam mammals collected by Prince Maximiliam zu Wied. Amer. Mus. Novitates, 2209: 1-21, N.York.

BARBOSA, L., 1951 - Pequeno vocabulário tupi-português. S. José, R. Janeiro.

BOSCHI, C.C., 1986 - Roteiro-sumário dos arquivos portugueses de interesse para o pesquisador da história do Brasil. Ed. Arquivos do Estado, S. Paulo.

CRULS, G., 1958 - Hilêia amazônica. José Olympio, R. Janeiro.

DELAUNA Y, Po, 1962 - La Zoologie au Seizième siècle. Hermann, Paris.

D’EVREUX, Y., 1615 - Historie des choses plus mémorables advenues en Maragnan en années 1613 et 1614. Paris.

D’EVREUX, Y., 1864 - Voyage dans le nord du Brésil fait durant les années 1613 et 1614. Publiê d’après l'exemplaire unique conservê a la Bibliothèque Impériale 
Vol. $6(3), 1989$

de Paris, Bibliotheca Americana, Coll.d’ouvrages inédits ou rares sur 1'Amérique. Leipzig \& Paris, A. Franck, Albert L. Herold.

D’EVREUX, Y., 1874 - Viagem ao norte do Brasil. Traduçäo de César Augusto Marques. Maranhäo. Reeditada em 1929, com nota explicativa de Humberto de Campos. Livraria Leite Ribeiro, R. Janeiro.

FONSECA, L., 1952 - Frei Cristóvão de Lisboa, O. F. M., missionary and natural historian of Brazil. The Americas, 8(2): 289-303.

FONSECA Fং.,O., 1973 - O Brasil e as ciências naturais nos séculos XVI a XVIII. Ci. Cult., 25(10): 946-957, S. Paulo,

FONSECA F.,O., 1973 - O Brasil e as ciências naturais nos séculos XVI a XVIII. (conclusăo). Ci. Cult., 25(10): 1015-1029. S. Paulo.

FRANÇA, C., 1926 - Os portugueses do século XVI e a história natural do Brasil. Rev. Hist., 15(57-60), Lisboa.

GAFFAREL, Pø, - Historie du Brésil Français au XVIIèmesiècle.

HERSHKOVITZ, P., 1988 - History of the recent mammalogy of the neotropical region from 1492 to 1850. Fieldiana, zool., 39:11-98.

LISBOA, C., 1967 - História dos animais e árvores do Maranhäo. Arquivo Histórico Ultramarino e Centro de Estudos Históricos Ultramarinos, Lisboa.

MAC CREAGH, G., 1961 - White waters and black, Doubleday. N. York.

MELlO-LEITÃO, C., 1937 - A biologia no Brasil. Ed. Nacional, S. Paulo

MELLO-LEITÃO, C., s/d - Botânica e zoologia. Manuscrito inédito.

MONES, A., 1973 - Estudios sobre la familia Hydrochoeridae (rodentia). Revta bras. Biolo, 33(2): 277-283, R. Janeiro.

MORAIS, R., 1936 - Anfiteatro amazônico. Melhoramentos, S. Paulo.

NEIV A, A., 1929 - Esboço histórico sobre a botânica e zoologia no Brasil de Gabriel Soares de Souza, 1587 a 7 de setembro de 1922. Soc. Imprensa Paulista, S. Paulo.

PEREIRA, M.O.N_, 1944 - O peixe-boi na amazônia. Bolm Minist. Agric., R. Janeiro.

PINA, L., 1942 - Para a história natural brasileira. Brasilica I, Coimbra.

PINTO, O.M.O., 1979 - A ornitologia do Brasil atravěs das idades (século XVI a século XIX). Brasiliensia Documenta, S. Paulo. 
SNETHLAGE, Ee, 1926 - Lista systematica de mammiferos do Estado do Maranhão collecionados por E.Snethlage. Bolm Mus. Nac., 2(6): 35-36, R. Janeiro.

STRADELLI, E., 1929 - Vocabulários da lingua geral portuguez-nheêngatu e nheêngatuportuguez. Revta Inst. Hist. Geogr. Brasil, 104(158): 5-768, R. Janeiro.

TASTEVIN, C., 1923 - Nomes de plantas e animaes em lingua tupy. Rev! Mus. Paulista, 13: 1-77, S. Paulo.

TAUNAY, A.E., 1937 - Monstros e monstrengos do Brasil. Revta Mus. Paulista, 21, S. Paulo.

TAUNAY, A.E., 1938 - Visitantes do Brasil colonial. (Séculos XVI - X VIII). Segunda edição, Ed. Nacional, S. Paulo.

VIEIRA, C.O.C. 1957 - Sobre mamfferos do estado do Maranhãu. Papeis Avul. S. Paulo, 13: 125-132, S. Paulo.

WIED, M., 1820 - Reise nach Brasilien. Frankfurt a.M.

WIED, M., 1826 - Beiträge zur Naturgeschichte von Brasilien, vol II., Weimar.

WIED, M., 1940 - Viagem ao Brasil. Tradução e notas de O.M.O. Pinto Ed. Nacional, S. Paulo.

\section{PRANCHAS}

As estampas äparecem na mesma ordem do texto e com a mesma numeração original, de Frei Cristóvão de Lisboa.

\section{AGRADECIMENTO}

À Adriana Mohr, pela leitura crítica e datilografia dos originais. 